\title{
Electromagnetic Finite Element Calculations of Permanent Magnet Generators for ECOBulb and HYDROMATRIX ${ }^{\mathrm{TM}}$ Applications
}

\author{
E. Schlemmer and F. Müller \\ Engineering Manufacturing Electrical (EL) - Generators, Engineering Development (EL-ED1) \\ VA TECH HYDRO GmbH \& Co \\ Elingasse 3, 8160 Weiz (Austria) \\ phone:+43 3172606 2812, fax:+43 31726062098 , \\ e-mail: Erwin.Schlemmer@vatech-hydro.at, Franz.Mueller@vatech-hydro.at
}

\begin{abstract}
Although HYDROMATRIX ${ }^{\mathrm{TM}}$ and ECOBulb ${ }^{\mathrm{TM}}$ technologies are relatively new, they can be considered as a ecologically and economically sound method for the generation of electric energy. With the advent of high energy permanent magnets, several restrictions in geometrical dimensioning have become much less severe. The use of permanent magnets for the excitation of synchronous generators has several beneficial effects such as the improvement of the load factor (compared with asynchronous generators) and the elimination of the ohmic losses in the field coils. Nevertheless, the use of permanent magnets poses several challenges for the design engineer. One of them is the exact prediction of the induced voltage since there is no possibility to re-adjust the voltage by a field current. Second, there is the possibility of de-magnetisation of the magnets in the event of an short circuit which has to be prevented. Additionally, the slot ripple losses in the surface of the rotor parts tends to increase the magnets' temperature which makes them more vulnerable against de-magnetisation in the case of a short-circuit. The application of modern computation methods to the mentioned problems will be demonstrated in this paper.
\end{abstract}

\section{Key words}

Finite element methods, synchronous generators, permanent magnet excitation, eddy currents, losses.

\section{Introduction}

The HYDROMATRIX ${ }^{\mathrm{TM}}$ technology [1] is one of the most economically viable solutions for the generation of renewable energy from hydropower. It utilises existing dam structures where more or several dam gates are replaced by so-called modules consisting of several dozens of small scale (approx. $500 \mathrm{~kW}$ ) generators. Therefore, the major source of cost in the construction of a hydro power plant, namely civil works, is reduced to a moderate amount. Fig. 1 shows a HYDROMATRIX ${ }^{\mathrm{TM}}$ module (a) and the close-up of a single asynchronous generator as one of the major constituents of a module (b).

Asynchronous generators, especially those directly driven with high pole numbers, suffer from low load factors which has the consequence that the magnetising energy for the generator must either be furnished by the grid or by capacitor banks.

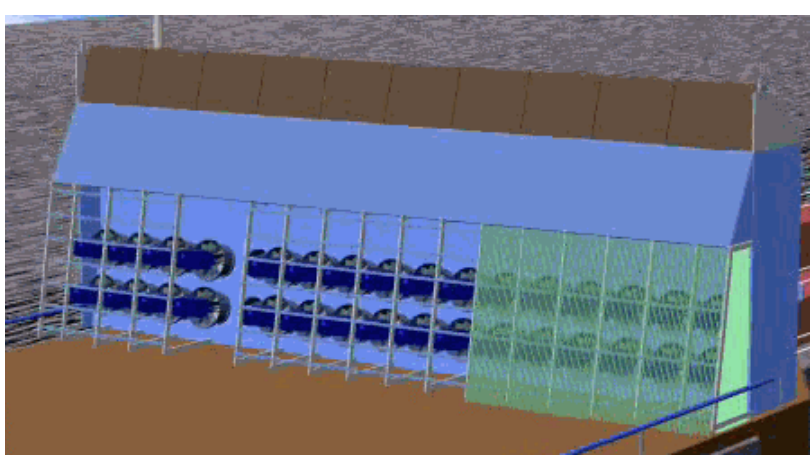

(a)

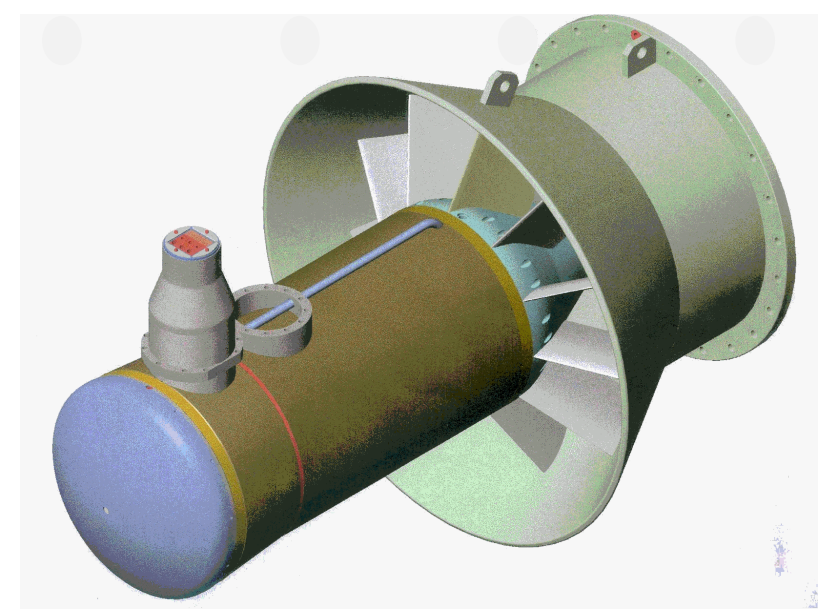

(b)

Fig. 1. HYDROMATRIX ${ }^{\mathrm{TM}}$ module (a) and asynchronous generator (b).

Grid operators might not be willing to provide considerable amounts of reactive power. The use of capacitors might impose several problems from cost considerations as well as from the point of view of module weight and stiffness. The cost argument is sometimes offset by the very simple concept of the asynchronous machine. Fig. 2 exhibits such an asynchronous generator for a HYDROMATRIX ${ }^{\mathrm{TM}}$ project at the test field. 


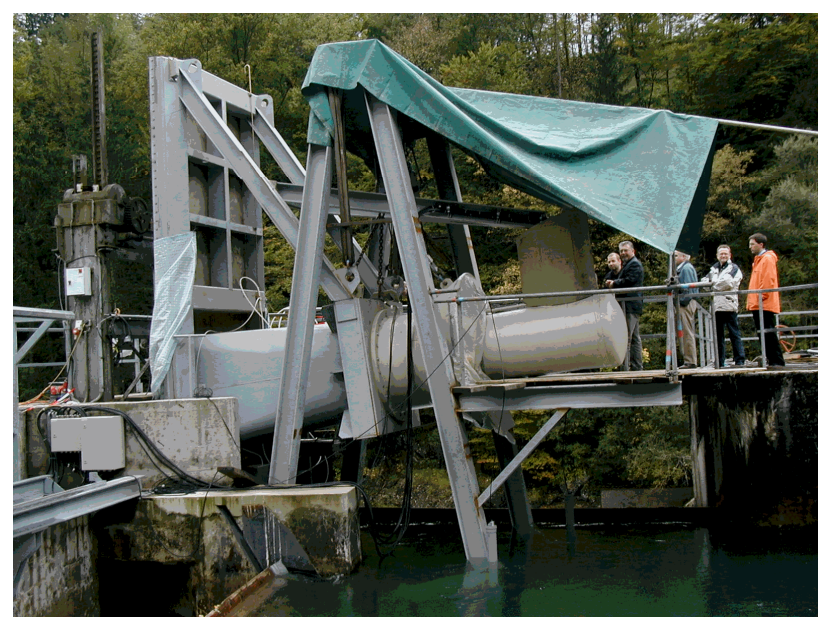

Fig. 2. HYDROMATRIX ${ }^{\mathrm{TM}}$ asynchronous generator at the test site Agonitz, [2].

To circumvent the problems associated with direct driven asynchronous generators, the concept of permanent magnet (PM) excited synchronous generators has been adopted to being used in a matrix environment. Fig. 3 shows the equivalent PM excited generator of the StrafloMatrix $^{\mathrm{TM}}$ type at the test site, [2].

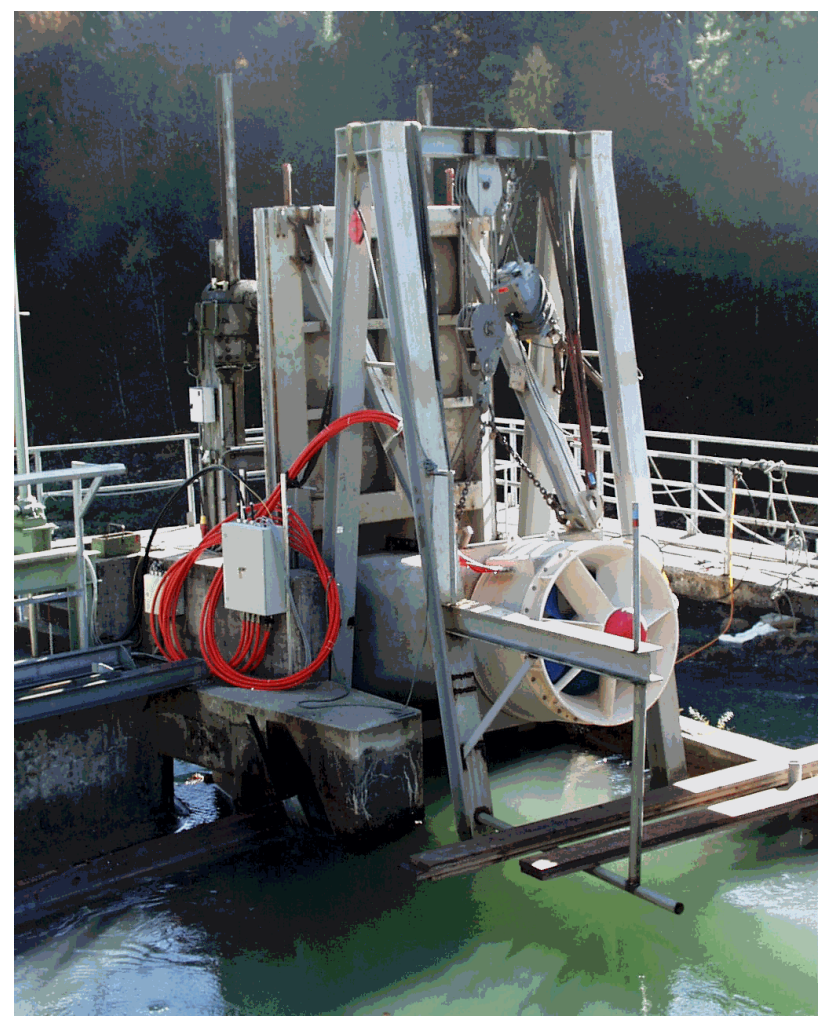

Fig. 3. Straflo-Matrix ${ }^{\mathrm{TM}}$ synchronous generator at the test site, [2].

According to [2], the particularity of the Straflo-Matrix ${ }^{\mathrm{TM}}$ concept, which is a further development step of the HYDROMATRIX ${ }^{\mathrm{TM}}$ turbine, is the turbine runner ring that carries the generator rotor yoke. The prototype of the new concept has been tested on site during autumn 2002. After the Agonitz plant has been re-built, the world's first commercial used Straflo-Matrix ${ }^{\mathrm{TM}}$ turbine will be installed there by the beginning of 2004 .

The suite of ECOBulb ${ }^{\mathrm{TM}}$ [3] machines (Fig. 4) represents a series of small to medium directly driven bulb type generators (from $200 \mathrm{~kW}$ to $5 \mathrm{MW}$ ) with permanent magnet excitation, integrated cooling and without oil filling or gear box. The elimination of the step-up gear has economical effects in terms of efficiency increase and cost reduction. However, direct driven units are associated with high pole numbers. These lead to several problems. First, due to the small pole pitch, a classical solution with poles and field coils might not be feasible due to space restrictions. Second, the larger diameters of the units might disturb the flow around the bulbs thus reducing hydraulic efficiency. The use of high energy permanent magnets as means for excitation has several important advantages. The space pole pitch restrictions are very much relieved. Moreover, with rare earth magnets, the necessary magnet thickness is comparably low which results in a relatively small increase in rotor diameter due to magnet height.

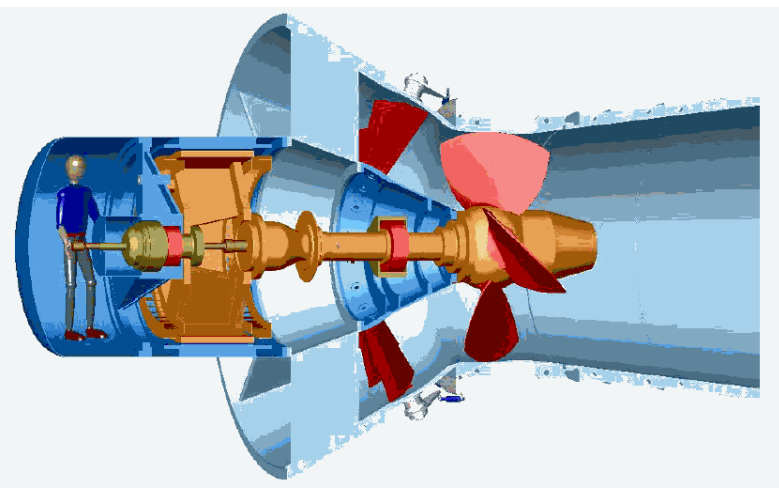

Fig. 4. CAD drawing of ECOBulb ${ }^{\mathrm{TM}}$ unit [4].

In Fig. 5, the moderate diameter of the bulb can be assessed from the CAD drawing of bulb integration into the plant. Therefore, the axial flow has a very good characteristics thus increasing the hydraulic efficiency of the units [4].

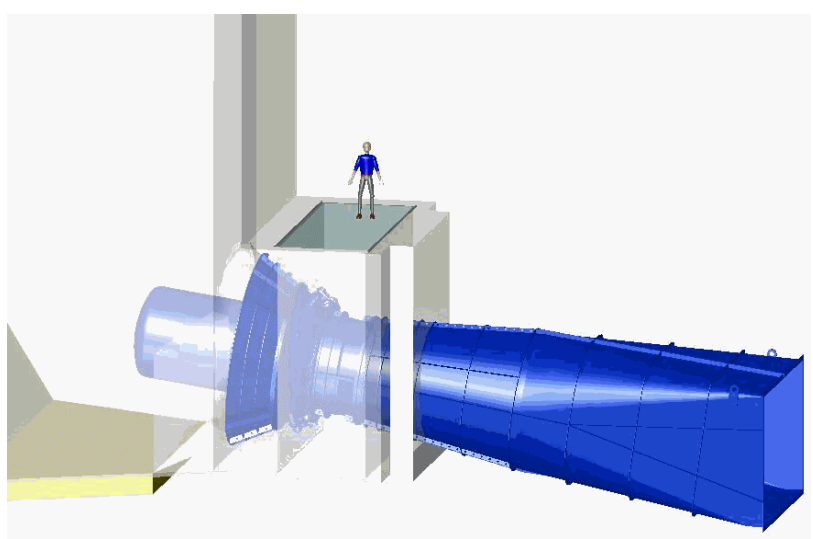

Fig. 5. Integration of an ECOBulb ${ }^{\mathrm{TM}}$ unit into the plant [4]. 


\section{Electromagnetic Finite Element Calculations}

Besides major advantages, such as the elimination of field coils and exciter losses, the use of permanent magnets also exhibits some problems [5]. PM excited generators do not have any possibility to re-adjust the design voltage so the design should be carried out by a reliable numerical method. Moreover, the load factor at nominal load is a function of grid voltage and current. Therefore, the effects of armature reactions have to be taken into account as good as possible. Additionally, pole surface losses ([6], [7]) can heat up the magnet thus endangering its magnetisation in the case of a short circuit. In order do reduce the slot ripple, magnetic slot wedges are employed frequently. The use of numerical methods becomes nearly mandatory when trying to assess the effects of magnetic wedges. In order to ensure sufficient stability for generators connected directly to the grid, i.e. without frequency converter, an adequate damper structure has to be provided. A very simple and convenient way to do so is the use of a canned rotor [8] which has also the merit of sealing the magnets hermetically. In the case of larger rotor diameters, the use of canned rotors might not be feasible any more. In these cases, other structures such as covers for single poles are used. Applications of the FEM to these problems will be given in the next sections.

\section{A. Induced Voltage}

With the use of a time-stepped finite element method, the induced voltages are a by-product of every calculation of eddy currents. Given the correct magnetisation state of the PMs and the saturation of the magnetic circuit, induced voltages in the stator coils are given by the line integral of the magnetic vector potential around the coils. In two dimensional calculations (2d), this simplifies to the difference of the vector potentials between the two coil sides. An example of the line to ground voltage of a PM generator with constant air gap is given in Fig. 6. In this case, a sintered $\mathrm{NdFeB}$ magnet with an energy product of 38-40 MGOe and a Curie Temperature of 310$350^{\circ} \mathrm{C}$ was used.

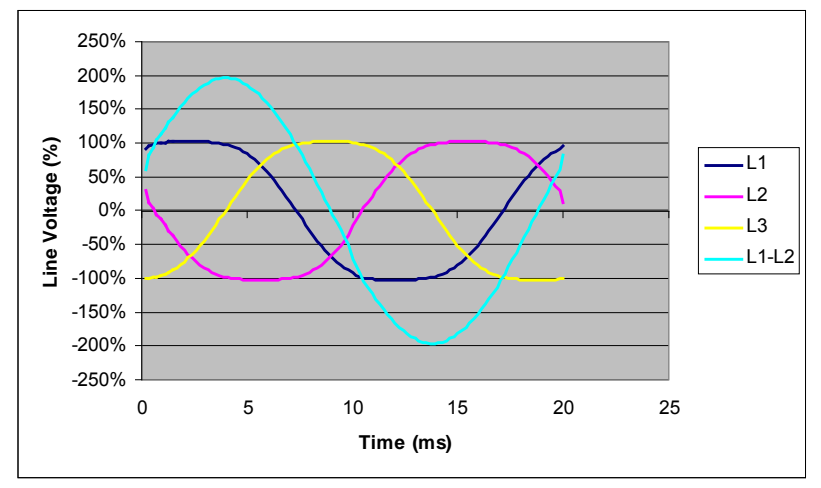

Fig. 6. Calculated induced line to ground voltage and line to line voltage for canned rotor runner at open circuit.
Taking armature reaction into consideration, the induced voltage show the characteristic distortion as can be seen in Fig. 7. The same holds for short circuit calculations which are important for the estimation of the magnets behaviour with respect to de-magnetisation under reverse field conditions. Fig. 8 shows an example of a short circuit, albeit with an additional external reactance.

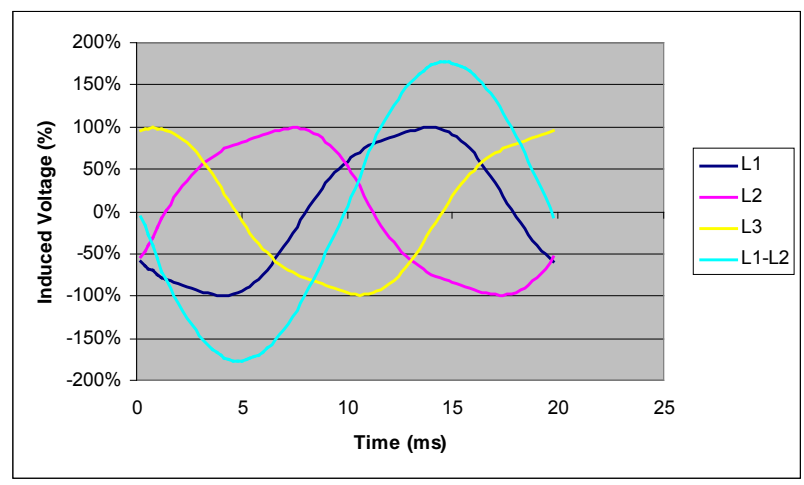

Fig. 7. Calculated induced line to ground voltage and line to line voltage for canned rotor runner at rated load.

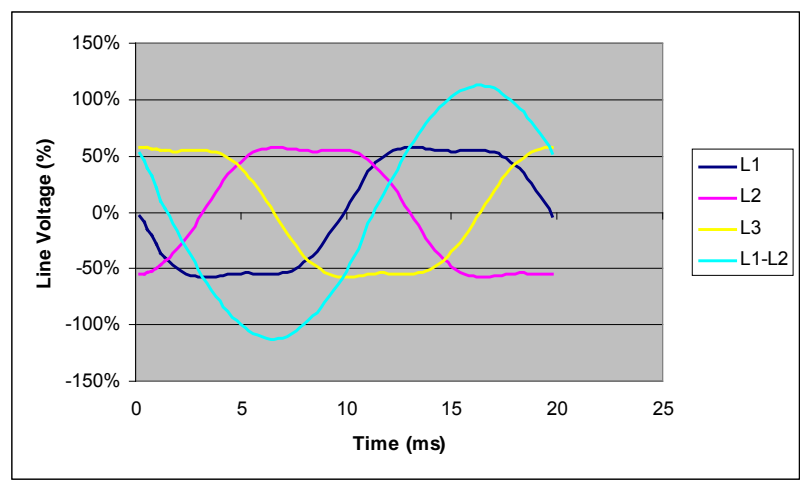

Fig. 8. Calculated induced line to ground voltage and line to line voltage for canned rotor runner at short circuit.

\section{B Rotor Losses due to Stator Slot Ripple}

The difference in permeance between stator teeth and slots causes flux variation along the stator surface. Although the main flux is stationary with respect to the rotor frame, the varying permeance values along the slots and teeth cause a flux variation along the pole surface which is proportional the circumferential speed, the ratio slot width to tooth width and the inverse proportional to the air gap. In order to reduce flux pulsations, magnetic slot wedges are employed, especially when the above mentioned values become critical. Fig. 9 exhibits the eddy current patterns for a generator with sine field poles and a thin pole cap under negative sequence conditions ( $8 \%$ negative sequence currents according to IEC).

As might be expected, 2d solutions are always approximate. This becomes ever more true when generators have a relatively small axial length or when they exhibit special constructive features, such as a gridlike pole cap. 


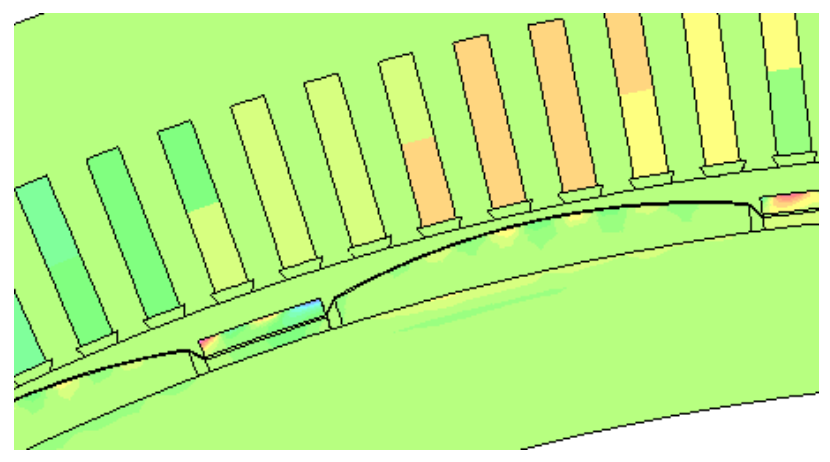

Fig. 9. Eddy current density on the surface of a fully capped PM rotor, 2d-calculation.

Fig. 10 supports the view that the eddy current patterns are relatively uniform along the axis. In Fig. 10, the model of Fig. 9 was reduced to four poles and three magnets in axial direction due to computation time restrictions [9].

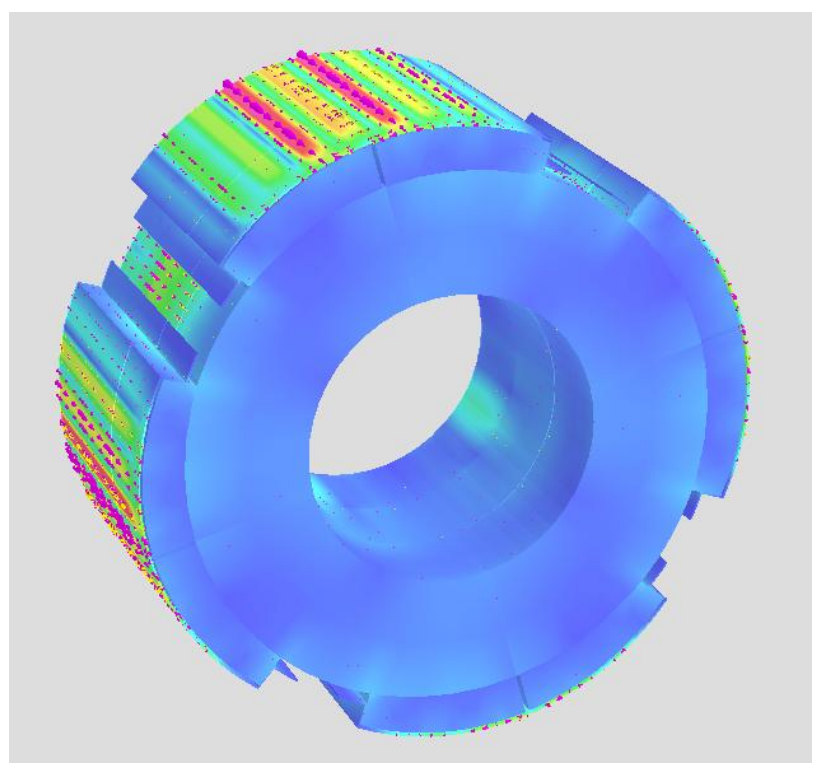

Fig. 10. Calculated eddy current density on the surface of a fully capped PM rotor.

Fig. 11 gives an impression of the eddy currents in the magnets under the protective cover. In this case, magnets and cover are not connected. That is, except on the lateral parts, no currents can traverse from the cover onto the magnets or vice versa.

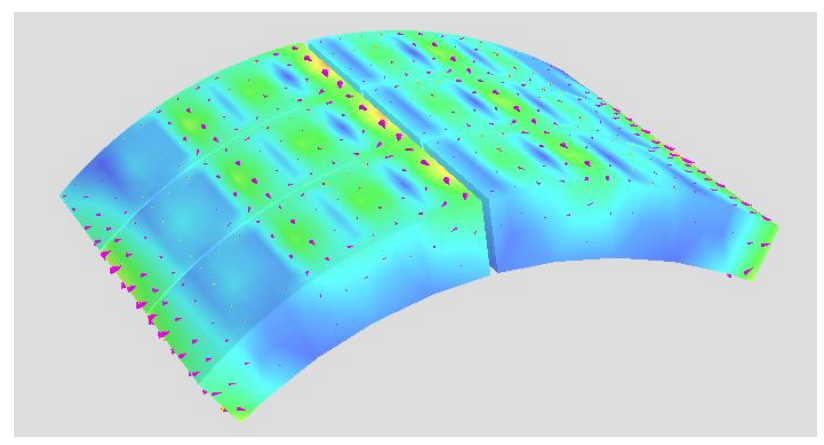

Fig. 11. Calculated eddy current density on the magnet of a fully capped PM rotor.
Due to the magnetic forces and the used adhesive, the magnets are not endangered of being thrown off the rotor yoke, even in case of over-speed. However, for safety reasons, an additional holding structure of stainless steel is employed in order to hold the magnets back in the extremely unlikely event of simultaneous demagnetisation of the magnets and rupture of the adhesive layer. For several reasons, amongst of which is loss reduction, a grid like structure is used.

Fig. 12 exhibits the modified eddy current pattern on the grid-like cover and from this figure, it becomes evident that a $2 \mathrm{~d}$ solution is not feasible in this very case.

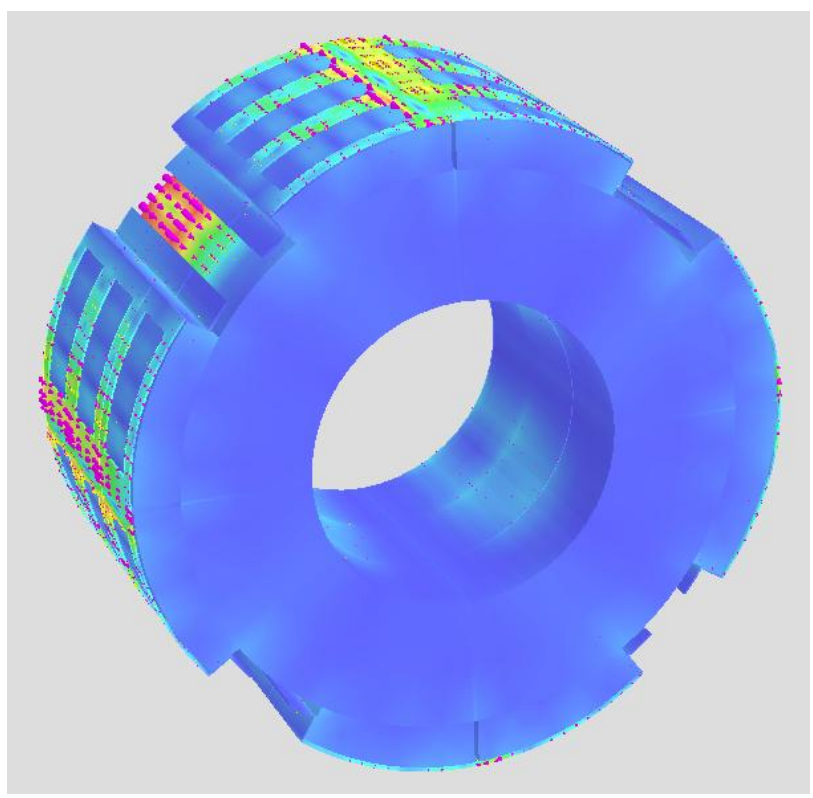

Fig. 12. Calculated eddy current density on the surface of a partly capped PM rotor.

Since there is no contact between cover and magnets, eddy current losses in the magnets are not increased significantly. Table I summarises the results for different configurations of the eddy current losses under negative sequence conditions. In the first column, the situation with respect to electrical contact between steel cap and magnets is described. "no" indicates that no current can cross from magnet to cap or vice versa; "yes" means that non-impeded current flow is possible. The second column indicates the configuration of the steel caps. In the "full"-case, the cap is made from a solid sheet of stainless steel, without holes. On the other hand, "grid" stands for the described case where each magnet is only covered on the vicinity of its rim, the centre of the magnets is therefore not covered by the steel cap.

TABLE I. - Eddy Current Losses for Different Configurations.

\begin{tabular}{|c|c|c|c|c|c|}
\hline \multicolumn{2}{|c|}{ CONFIGURATION } & \multicolumn{4}{|c|}{ POWER Losses IN } \\
\hline $\begin{array}{c}\text { Contact, Caps } \\
\text { and Magnets }\end{array}$ & $\begin{array}{c}\text { Caps } \\
\text { Config. }\end{array}$ & Caps & Magnets & Damper & Sum \\
\cline { 3 - 6 } & & $\%$ & $\%$ & $\%$ & $\%$ \\
\hline no & full & $27 \%$ & $15 \%$ & $38 \%$ & $80 \%$ \\
\hline no & grid & $11 \%$ & $15 \%$ & $52 \%$ & $77 \%$ \\
\hline yes & full & $24 \%$ & $18 \%$ & $59 \%$ & $100 \%$ \\
\hline yes & grid & $14 \%$ & $17 \%$ & $58 \%$ & $90 \%$ \\
\hline
\end{tabular}


Fig. 13 depicts the eddy current density on the can of the PM rotor shown in Fig. 3. Although having a higher pole number, the model once again was reduced to four poles for the sake of computational resources. The results for the eddy current losses showed a good agreement between measured and calculated values (Fig. 12).

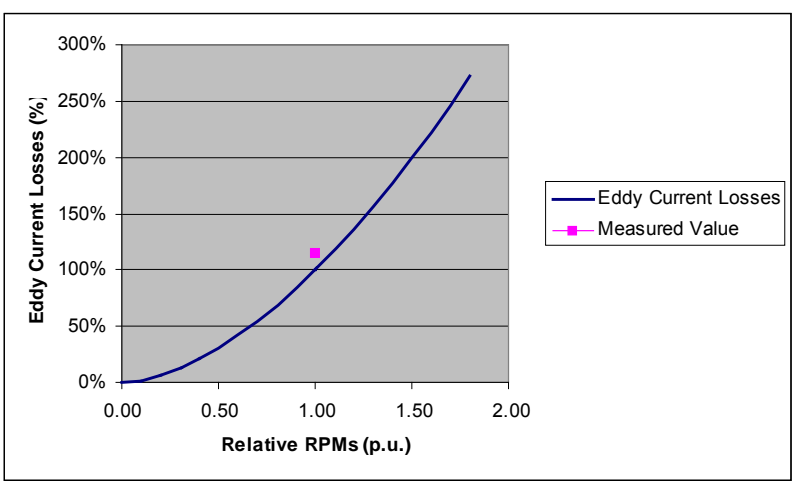

Fig. 12. Eddy current losses over mechanical frequency of the turbine.

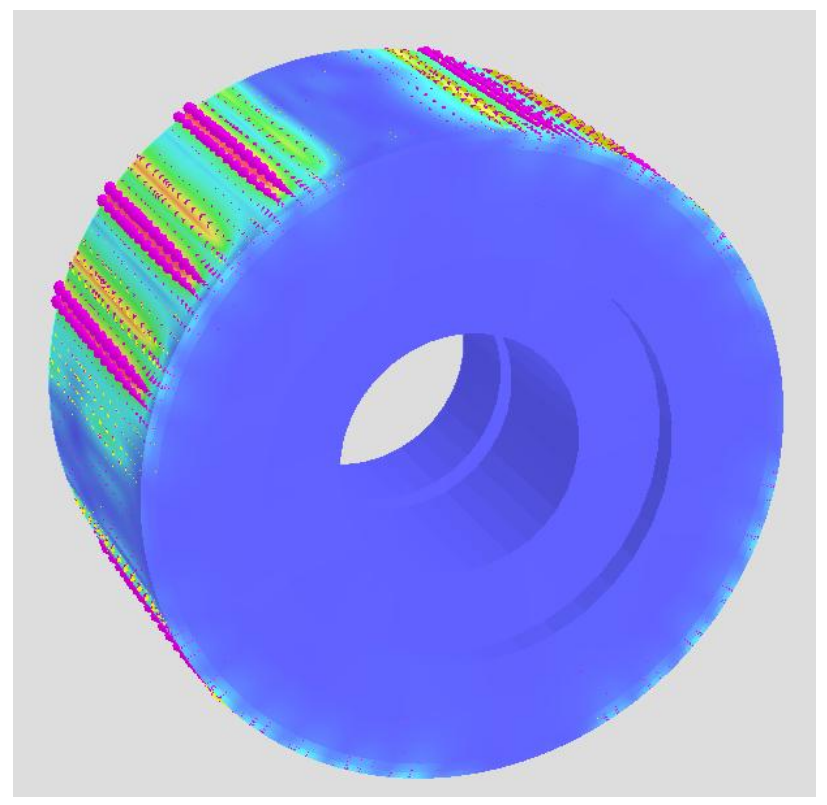

Fig. 13. Calculated eddy current density on the canned PM rotor.

\section{Conclusion}

During the last years, several important innovations in the field of hydro power generation have been introduced by VA TECH HYDRO. In the development of ECOBulb $^{\mathrm{TM}}$ and HYDROMATRIX ${ }^{\mathrm{TM}}$ generators, modern calculation methods have been applied extensively. In this paper, several problems of the electromagnetic engineering process of permanent magnet excited generators are dealt with. Examples of the evaluation of induced voltage, armature reaction and eddy current losses are given.

\section{Acknowledgement}

The financial support of the Austrian Forschungsförderungsfonds der gewerblichen Wirtschaft (FFF), grant no. 805011, and the Steirische Wirtschaftsförderung is gratefully acknowledged.

\section{References}

[1] Quinlan, B. and Bihlmayer, A.C., "Smithland and Cannelton HYDROMATRIX® projects - a new concept in hydroelectric power generation on the Ohio river", Proc. Hydrovision 2002, July 29 August 2, 2002, Portland, Oregon, USA.

[2] Scheidl, U., "Neue Turbinen für Kraftwerk Agonitz (New turbines for power plant Agonitz)", in German, e\&i, elektrotechnik und informationstechnik, Heft 1, 2003, p. a14.

[3] Duflon, P., "Technical features of the ECOBulb turbine-generator-unit", Proc. Hydro 2002, 4-7 November 2002, Kiris, Turkey, pp. 225-229.

[4] Duflon, P., Fonkenell, J., "ECOBulb" a technological breakthrough", HYDRO news, Customer magazine of VA TECH HYDRO, Nov. 2002, issue 03, pp 4-5.

[5] Zhu, Z. Q., Jewell, G. W., and Howe, D., "Finite element analysis in the design of permanent magnet machines", Proc. IEE Seminar on Current Trends in the Use of Finite Elements (FE) in Electromechanical Design and Analysis, pp. 1/1 1/7, 2000.

[6] Abu Sharkh,, S. M., Harris, M. R., and Taghizadeh Irenji, N., "Calculation of rotor eddy-current loss in high-speed PM alternators", Proc. Eighth International Conference on Electrical Machines and Drives, p. 170-174, 1997.

[7] Yoshida, K., Hita, Y., and Kesamaru, K., "Eddycurrent loss analysis in PM of surface-mounted-PM SM for electric vehicles", IEEE Trans. Magn, Vol. 36, No. 4, pp. 1941-1944, July 2000.

[8] Binns, K. J., Chaaban, F. B., and Hameed, A. A. K., "Major design parameters of a solid canned permanent magnet motor with skewed magnets", IEE Proceedings-B, vol. 140, no. 3, pp. 161-165, May 1993.

[9] Schlemmer, E., Klammler, F., and Müller, F., "Comparison of different numerical approaches for the calculation of eddy current losses in large synchronous generators", Proceedings of ELECTRIMACS 2002 (CD-ROM), August 18-21, 2002, Montréal, Québec, Canada. 